\title{
Potentiation and inhibition of migration of human neutrophils by auranofin
}

\author{
Jan G R Elferink, Ben M de Koster
}

\begin{abstract}
Objectives-As auranofin resembles some neutrophil activating sulphur containing compounds, it was decided to investigate whether it had activating effects on neutrophil migration in addition to the published inhibitory effects.

Methods-The Boyden chamber assay was used to determine the migration velocity of human neutrophils. The difference between chemotaxis and chemokinesis was established with a chequerboard assay.

Results-Low concentrations of auranofin stimulated human neutrophil migration; concentrations of auranofin higher than $1 \mu \mathrm{mol} / \mathrm{l}$ were inhibitory. Inhibitors of leukotriene formation, or of protein kinase $C$, had the same effect on auranofin induced potentiation of migration as on fMLP activated migration. Auranofin, at a concentration of $100 \mathrm{nmol} / \mathrm{h}$, caused a transient increase in the cGMP level of neutrophils. The auranofin induced increase in migration was strongly inhibited

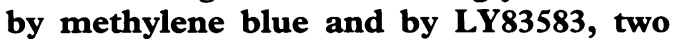
inhibitors of cGMP accumulation.

Conclusions-The auranofin induced enhancement of migration is partly due to a chemokinetic effect, but mainly due to a chemotactic effect. The potentiating effect of auranofin on migration is not specifically due to the ability of the drug to inhibit protein kinase $C$ activity or to generate leukotrienes. These results suggest that the enhancement of neutrophil migration by low levels of auranofin is related to the enhancement of cGMP levels in neutrophils.
\end{abstract}

(Ann Rheum Dis 1993; 52: 595-598)

Auranofin is a sulphur containing gold compound which is effective in the treatment of rheumatoid arthritis. The precise mechanism by which auranofin exerts its beneficial effect in arthritis is not known. The neutrophil is known to be an effector cell in inflammatory disorders and therefore many studies have been devoted to the interaction of auranofin with neutrophils. ${ }^{1-10}$

The effect of auranofin on neutrophil chemotaxis has been studied by several workers. ${ }^{1-5}$ The drug inhibits neutrophil chemotaxis in the micromolar concentration range. In vivo studies showed an inhibition of neutrophil chemotaxis of patients receiving auranofin; ${ }^{1}$ in some studies, however, a potentiation of chemotaxis was found. ${ }^{5}$
A number of other functions of the stimulated neutrophil are inhibited by auranofin. These include aggregation, phagocytosis, the release of lysosomal enzymes and leukotrienes, and the respiratory burst. ${ }^{6-10}$ Auranofin inhibits some cellular processes which might be related to inhibition of the functions. Protein kinase C activity, and the associated protein phosphorylation, are inhibited by auranofin. ${ }^{11} 12$ The drug inhibits the number of microtubules in resting neutrophils and decreases the surface charge and membrane potential of these cells. ${ }^{13}$

A number of studies have shown that auranofin is not only inhibitory but is also able to potentiate some functions and processes in the neutrophil and in other cell types. Although micromolar concentrations of auranofin inhibited the effect of phorbol myristate acetate, lower concentrations enhanced phorbol myristate acetate induced superoxide production. ${ }^{9}$ Low concentrations of auranofin stimulated interleukin 2 production, whereas high concentrations were inhibitory. ${ }^{14}$ Synthesis of leukotrienes was enhanced by low concentrations of auranofin. ${ }^{15}$ Auranofin may apparently show activating and inhibitory effects, depending on the conditions.

It has been found that a number of sulphur containing disease modifying drugs have a potentiating effect on migration and exocytosis by neutrophils. ${ }^{16-18}$ As there are some similarities between these compounds and auranofin, we decided to investigate whether auranofin has activating effects on neutrophil migration in addition to the published inhibitory effects.

\section{Materials and methods}

ISOLATION OF NEUTROPHILS

Human neutrophils were isolated from the venous blood of healthy volunteers using dextran sedimentation followed by centrifugation over Ficoll-Isopaque and hypotonic haemolysis of contaminating erythrocytes. Isolated neutrophils were resuspended in a medium containing $140 \mathrm{mmol} / \mathrm{l} \mathrm{NaCl}$, $5 \mathrm{mmol} / \mathrm{K} \mathrm{KCl}, 10 \mathrm{mmol} / \mathrm{g}$ glucose, $20 \mathrm{mmol} / \mathrm{l}$ HEPES ( $\mathrm{pH} 7 \cdot 3$ ), and $0.5 \%$ bovine serum albumin. The final neutrophil concentration during the experiments was $3 \times 10^{6} / \mathrm{ml}$.

MIGRATION MEASUREMENTS

Cell migration was measured with the Boyden chamber technique as described by Boyden, ${ }^{19}$ and modified by Zigmond and Hirsch. ${ }^{20}$ The two compartments of the chamber were separated by a cellulose acetate Millipore filter 
Figure 1 Effect of increasing concentrations of auranofin on neutrophil migration. Auranofin was present in the lower chamber only. compartment of the Boyden

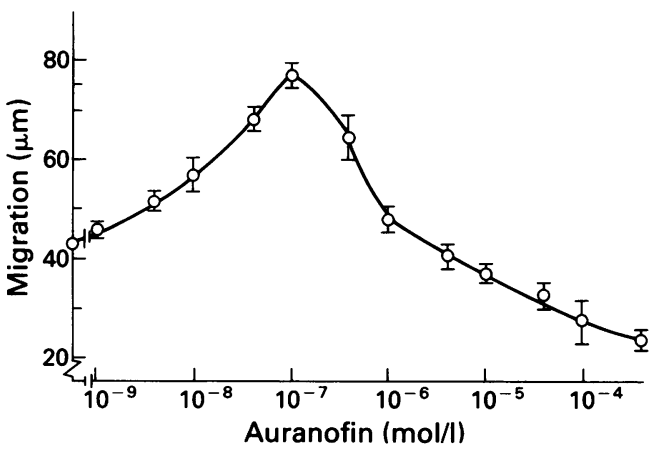

with a pore size of $3 \mu \mathrm{m}$. Medium supplemented with $1 \mathrm{mmol} / 1 \mathrm{Ca}^{2+}$ and $1 \mathrm{mmol} / 1 \mathrm{Mg}^{2+}$ was present in the upper and lower compartments, unless otherwise indicated. Neutrophils were placed in the upper compartment of the chamber then incubated for 40 minutes at $37^{\circ} \mathrm{C}$. After migration the filters were fixed and stained and the distance travelled in micrometres into the filter was determined according to the leading front technique. ${ }^{20}$

\section{CYCLIC GMP ASSAY}

Neutrophils (150 $\mu \mathrm{l}$; final concentration $2 \times 10^{7}$ cells $/ \mathrm{ml}$ ) were exposed to reagents at $37^{\circ} \mathrm{C}$ for the indicated time. Subsequently $150 \mu \mathrm{l} 3.5 \%$ perchloric acid was added, and the resulting mixture was stored overnight in a freezer. The solution was neutralised by adding $75 \mu$ l saturated $\left(22^{\circ} \mathrm{C}\right) \mathrm{NaHCO}_{3}$. After 10 minutes the mixture was centrifuged. To $100 \mu \mathrm{l}$ supernatant $50 \mu \mathrm{l}$ radioactive cGMP and $50 \mu \mathrm{l}$ antibody from the radioimmunoassay kit (Amersham) were added. After mixing the solution was stored on ice for 90 minutes, after which $1 \mathrm{ml}$ ice cold $60 \%$ $\left(\mathrm{NH}_{4}\right)_{2} \mathrm{SO}_{4}$ was added. The solution was mixed and stored on ice for a further 10 minutes, then centrifuged. The supernatant was carefully removed and the residue taken up in $1.1 \mathrm{ml}$ water. A $1 \mathrm{ml}$ volume of the solution was mixed with $4 \mathrm{ml}$ scintillation fluid (299, Packard), and counted in a scintillation counter. Known amounts of cGMP were treated in the same way as the cells and were used for the calibration graph.

STATISTICAL ANALYSIS

Chemotactic assays were carried out in triplicate and the migration distance of the neutrophils was determined at five different filter sites. All mean values are arithmetical

Table 1 Stimulation and inhibition of neutrophil migration by auranofin under various experimental conditions. Results are given as mean (SEM)

\begin{tabular}{|c|c|c|c|}
\hline \multicolumn{2}{|c|}{ Concentration of auranofin (moll) present in } & \multicolumn{2}{|c|}{ Migration towards filter $(\mu m)$} \\
\hline Lower compartment & Upper compartment & No additive & $f M L P$ \\
\hline - & - & $53.2(1.4)$ & $108 \cdot 2(1 \cdot 3)$ \\
\hline $1 \times 10^{-7}$ & $1 \times 10^{-7}$ & $64 \cdot 1(0 \cdot 7)$ & $106.8(1.5)$ \\
\hline & $1 \times 10^{-7}$ & $56 \cdot 3(1 \cdot 1)$ & $107.5(1.9)$ \\
\hline $1 \times 10^{-7}$ & - & $81.0(1 \cdot 3)$ & $109.8(1 \cdot 1)$ \\
\hline $2 \times 10^{-5}$ & $2 \times 10^{5}$ & $48 \cdot 2(1 \cdot 2)$ & $89 \cdot 3(0 \cdot 7)$ \\
\hline & $2 \times 10^{-5}$ & $52 \cdot 8(1.3)$ & $100 \cdot 7(1 \cdot 2)$ \\
\hline $2 \times 10^{-5}$ & - & $50 \cdot 6(1 \cdot 6)$ & $97 \cdot 7(1.0)$ \\
\hline
\end{tabular}

$\mathrm{fMLP}=1 \times 10^{-9} \mathrm{~mol} / \mathrm{fMet}-\mathrm{Leu}-\mathrm{Phe}$, present in the lower compartment of the Boyden chamber. means (SEM), calculated on the basis of all 15 determinations. The significance was calculated with Student's $t$ test; $\mathrm{p}<0.01$ was considered as statistically significant.

Results

Random migration by neutrophils was stimulated if auranofin was present in the lower compartment of the Boyden chamber in the concentration range up to $1 \mu \mathrm{mol} / 1$ (fig 1 ). Maximum stimulation occurred at a concentration of $0 \cdot 1 \mu \mathrm{mol} / \mathrm{l}$ auranofin. Concentrations of auranofin higher than $1 \mu \mathrm{mol} / \mathrm{l}$ inhibited random locomotion.

The effect of auranofin strongly depended on the location of the drug with respect to the cells, and whether or not a chemotactic agent was present (table 1). The activating effect was strong when auranofin $\left(1 \times 10^{-7} \mathrm{~mol} / \mathrm{l}\right)$ was present in the lower compartment only. When the drug was present in the two compartments the effect was moderate, and the effect was small when auranofin was present in the upper compartment with the cells.

The effect of auranofin on fMLP induced chemotaxis was tested. Auranofin $\left(10^{-7} \mathrm{~mol} / \mathrm{l}\right)$ had little effect when the chemotactic agent fMLP was present in the lower compartment. A concentration of $20 \mu \mathrm{mol} / 1$ auranofin was inhibitory, not only on random migration but especially on fMLP induced chemotaxis; the effect was most pronounced when the drug was present in the two compartments of the Boyden chamber (table 1).

A chequerboard assay was carried out to establish the relative contributions of chemokinesis and chemotaxis in auranofin stimulated neutrophil migration. Migration was higher than calculated on the basis of chemokinesis alone when the concentration of auranofin in the lower compartment was higher than in the upper compartment. The reverse was true when the concentration below the filter was lower than in the upper compartment (table 2).

To determine the possible involvement of leukotriene $\mathrm{B}_{4}$ in auranofin induced enhancement of migration, several inhibitors of leukotriene formation were tested. These inhibitors (naproxen, felodipine, nordihydroguaiaretic acid, and quercetin) were tested in concentrations which are known to inhibit strongly leukotriene formation. ${ }^{21}$ As a control the effect of these inhibitors on fMLP induced migration was tested. Inhibition of auranofin induced migration was about the same as that of fMLP induced migration (table 3). As auranofin affects protein kinase $\mathrm{C}$ mediated neutrophil functions the same procedure was followed to determine a role for protein kinase C in the activating effect of auranofin. Two specific inhibitors of protein kinase $\mathrm{C}$, staurosporine and 1-O-hexadecyl-2-O-methylglycerol (AMG-C 16 ), ${ }^{22}$ gave no more inhibition of migration with auranofin as an activating agent than with fMLP.

Auranofin, at a concentration of $1 \times 10^{-7}$ mol/l, enhanced the cGMP level of resting neutrophils. The effect is transient, and a 
Table 2 Migration of neutrophils in different absolute concentrations and concentration gradients of auranofin

\begin{tabular}{|c|c|c|c|c|c|}
\hline \multirow{2}{*}{$\begin{array}{l}\text { Concentration of auranofin } \\
\text { in upper compartment } \\
\text { (moll) }\end{array}$} & \multicolumn{5}{|c|}{ Concentration of auranofin in lower compartment (moll) } \\
\hline & 0 & $1 \times 10^{-9}$ & $5 \times 10^{-9}$ & $2 \times 10^{-8}$ & $1 \times 10^{-7}$ \\
\hline $\begin{array}{l}0 \\
1 \times 10^{-9} \\
5 \times 10^{-9} \\
2 \times 10^{-8} \\
1 \times 10^{-7}\end{array}$ & $47 \cdot 5(1 \cdot 4)$ & $\begin{array}{l}48 \cdot 4(1 \cdot 0) \\
49 \cdot 9(1 \cdot 1)[50] \\
50 \cdot 4(1 \cdot 8)[56] \\
50 \cdot 1(1 \cdot 3)[61]\end{array}$ & $\begin{array}{l}52 \cdot 1(1 \cdot 4)[49] \\
51 \cdot 0(0 \cdot 7) \\
53 \cdot 0(1 \cdot 7)[56] \\
49 \cdot 8(1 \cdot 5)[62]\end{array}$ & $\begin{array}{l}62 \cdot 4(1 \cdot 6)[50] \\
59 \cdot 9(1 \cdot 8)[52] \\
57.5(1 \cdot 1)[63] \\
55.5(2 \cdot 2)[63]\end{array}$ & $\begin{array}{l}73 \cdot 3(1.5)[52] \\
71 \cdot 0(1.4)[54] \\
69 \cdot 3(1 \cdot 1)[59] \\
64 \cdot 9(1.5)\end{array}$ \\
\hline
\end{tabular}

Values given represent the mean (SEM) migration $(\mu \mathrm{m})$ into the filter after an incubation time of 40 minutes, in the presence of the indicated concentrations of auranofin below and above the filter. The values in square brackets are the migration values expected on the basis of the effects of chemokinesis alone (calculated according to Zigmond and Hirsch ${ }^{20}$ ).

Table 3 Inhibition of $f M L P$ or auranofin enhanced migration of neutrophils by inhibitors of leukotriene formation or protein kinase $C$ inhibitors

\begin{tabular}{lll}
\hline Inhibitor & \multicolumn{2}{l}{ Migration towards $(\mu \mathrm{m})$} \\
\cline { 2 - 3 } & $f M L P$ & Auranofin \\
\hline- & $99 \cdot 2(1 \cdot 4)$ & $78 \cdot 7(1 \cdot 3)$ \\
$50 \mu \mathrm{mol} / /$ naproxen & $83 \cdot 4(1 \cdot 2)$ & $78 \cdot 7(1 \cdot 7)$ \\
$5 \mu \mathrm{mol} / 1$ felodipine & $99 \cdot 3(1 \cdot 7)$ & $78 \cdot 3(1 \cdot 7)$ \\
$10 \mu \mathrm{mol} / /$ NDGA & $89 \cdot 9(1 \cdot 3)$ & $78 \cdot 9(1 \cdot 5)$ \\
$10 \mu \mathrm{mol} / /$ quercetin & $85 \cdot 2(1 \cdot 9)$ & $75 \cdot 1(1 \cdot 8)$ \\
$100 \mathrm{nmol} / /$ staurosporine & $80 \cdot 6(1 \cdot 5)$ & $64 \cdot 4(1 \cdot 1)$ \\
$100 \mu \mathrm{mol} / /$ AMG-C 16 & $91 \cdot 3(1 \cdot 6)$ & $76 \cdot 2(1 \cdot 9)$ \\
\hline
\end{tabular}

NDGA $=$ Nordihydroguaiaretic acid; $\mathrm{AMG}-\mathrm{C}_{16}=1-O$-hexadecyl$2-O$-methylglycerol. Auranofin $\left(1 \times 10^{-7} \mathrm{~mol} / \mathrm{l}\right)$ and $\mathrm{fMLP}$ $\left(1 \times 10^{-9} \mathrm{~mol} / \mathrm{h}\right)$ were present in the lower compartment only.

Migration in the absence of activating agent was $43.8(1 \cdot 7) \mu \mathrm{m}$

maximum effect was observed after the incubation of neutrophils for about five minutes with auranofin (fig 2).

Methylene blue, an inhibitor of cGMP accumulation, had little effect on random migration, but inhibited the enhancement of migration induced by a low concentration of auranofin. The inhibitory effect of a higher concentration of auranofin on fMLP induced migration was not decreased by methylene blue (table 4). LY83583, an inhibitor of guanylate cyclase, gave the same effects as methylene blue; the inhibitory effects were even more pronounced (table 4). Methylene blue and LY83583 were tested to see whether they inhibited auranofin induced cGMP

Figure 2 Time course of auranofin induced enhancement of cellular cGMP level. Cells were incubated with or without 100 nmoll auranofin for the indicated time at $37^{\circ} \mathrm{C}$ after which the cGMP level was determined. Values given are the mean (SEM) of three experiments.

$=$ control cells;

$\mathrm{O}=$ auranofin treated cells.

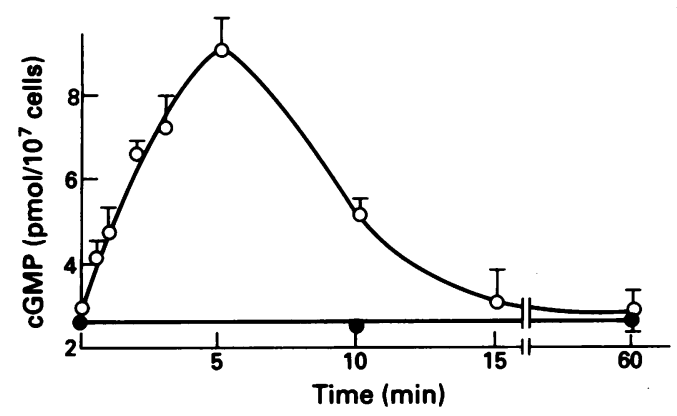

Table 4 Modulation of the activating and inhibitory effect of auranofin by methylene blue and by $L Y 83583$

\begin{tabular}{|c|c|c|c|}
\hline & Migration (A & & \\
\hline & $\begin{array}{l}\text { No agent } \\
\text { added }\end{array}$ & 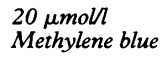 & $\begin{array}{l}10 \mu \mathrm{mol} \\
L Y 83583\end{array}$ \\
\hline - & $43 \cdot 1(1 \cdot 8)$ & $36 \cdot 4(1.4)$ & $36 \cdot 6(1 \cdot 3)$ \\
\hline $1 \times 10^{-7} \mathrm{~mol} / \mathrm{l}$ auranofin & $80 \cdot 1(2 \cdot 5)$ & $55 \cdot 8(1 \cdot 6)$ & $37 \cdot 1(1 \cdot 6)$ \\
\hline fMLP & $100 \cdot 3(1 \cdot 6)$ & $91.9(1.2)$ & $88.0(1.5)$ \\
\hline fMLP plus $2 \times 10^{-5} \mathrm{~mol} / 1$ auranofin & $73.3(1.5)$ & $68 \cdot 1(1 \cdot 3)$ & $63 \cdot 4(1.7)$ \\
\hline
\end{tabular}

The activating agents $\left(1 \times 10^{-7} \mathrm{~mol} / /\right.$ auranofin, $\left.1 \times 10^{-9} \mathrm{~mol} / / \mathrm{fMLP}\right)$ were only present in the lower compartment of the Boyden chamber; methylene blue, LY83583, and the inhibitory concentration of auranofin $\left(2 \times 10^{-5} \mathrm{~mol} / \mathrm{l}\right)$ were present in the two compartments. accumulation in neutrophils under the conditions of our experiments. Although auranofin $\left(1 \times 10^{-7} \mathrm{~mol} / \mathrm{l}\right.$, incubation time five minutes) gave an increase of cGMP from $2.5(0.2)$ to $12.6(1.6) \mathrm{pmol} / 10^{7}$ cells, the increase was reduced to $1.9(0.4) \mathrm{pmol} / 10^{7}$ cells in the presence of methylene blue, and to $2.3(0.3) \mathrm{pmol} / 10^{7}$ cells in the presence of LY83583. The inhibitors had little effect on the cGMP level of resting cells.

\section{Discussion}

The results presented here show that auranofin not only has inhibitory effects on migration, but that at low concentrations the drug stimulates neutrophil migration. The stimulating effect is partly chemokinetic because migration is enhanced when auranofin is present in the upper and lower compartments of the Boyden chamber. The strongest enhancement of migration is observed when the drug is present in the lower compartment only, indicating that auranofin also has chemotactic properties.

The relative contribution of chemokinesis and chemotaxis in the activating effect of auranofin on neutrophil migration can be derived from the chequerboard assay. ${ }^{23}$ This shows that chemotaxis and chemokinesis contribute to the enhancing effect on neutrophil migration. The chemotactic component, however, is stronger than the chemokinetic component.

At low concentrations auranofin stimulates leukotriene $\mathrm{B}_{4}$ generation. As this leukotriene is chemotactic it is conceivable that a relation exists between the generation of the leukotriene and the enhanced motility induced by auranofin. A series of inhibitors of leukotriene generation, however, had little effect on auranofin induced migration, and if there was a slight inhibition it was not more than for fMLP induced migration. This makes it unlikely that leukotriene formation affects the potentiating effect of auranofin on neutrophils. Protein kinase $C$ activity is required for the synthesis of leukotriene $B_{4}$ in neutrophils. ${ }^{24}$ Auranofin modulates some leucocyte functions by interacting with protein kinase C. ${ }^{11} 12$ Two inhibitors of protein kinase $\mathrm{C}$, in concentrations which completely inhibit the enzyme, have no more effect on auranofin induced migration than on fMLP induced migration. This suggests that the potentiating effect of auranofin on migration is not specifically mediated by protein kinase $\mathrm{C}$, and supports the view that leukotrienes do not play a part in this potentiating effect. 
A possible role for cGMP in neutrophil migration has been suggested. A number of different agents which have an enhancing effect on the cGMP level of cells also stimulate neutrophil migration. These agents include ascorbic acid, ${ }^{25}$ levamisole, ${ }^{26}$ acetyl choline, ${ }^{27}$ D-penicillamine, ${ }^{17}$ and others. ${ }^{28} 29$ Auranofin also causes an enhancement of the cGMP level in neutrophils. Though the role of cGMP in neutrophil functions is far from clear, it seems tempting to speculate that the enhancement of the cGMP level, or a process which is associated with this enhancement, is related to the activating effect of auranofin on neutrophil migration.

Apart from the enhancement of the cGMP level some other results support the hypothesis that cGMP plays a part in the activating effect of auranofin. Methylene blue and LY83583 are known inhibitors of cGMP accumulation which act via an interference with guanylate cyclase. $^{3031}$ They completely inhibit the auranofin induced enhancement of cGMP level in neutrophils. The auranofin induced enhancement of migration is equally completely inhibited by these agents, whereas they have moderate effects on random migration and IMLP activated chemotaxis.

The inhibitory effect of auranofin, which occurs at higher concentrations of the drug, is in contrast with the activating effect not affected by methylene blue. This suggests that the activating and inhibitory effect are not due to a concentration dependent effect of the same agent, such as cGMP.

Inhibition of neutrophil migration has been proposed as a possible explanation of the beneficial effect of the drug in rheumatoid arthritis because the neutrophil is considered as an important mediator in inflammatory disorders. The serum concentration of gold during the treatment of rheumatoid arthritis with auranofin is about $0.7 \mu \mathrm{g} / \mathrm{ml}(40 \mu \mathrm{g} / \mathrm{ml}$ auranofin) ${ }^{32}$ From this amount about $90 \%$ is bound to serum proteins. The resulting free concentration of auranofin, about $0.4 \mu \mathrm{mol} / \mathrm{l}$, lies in the range where activating effects might occur on neutrophil migration and other functions. It seems evident that there is no simple correlation between the beneficial effect of auranofin in rheumatoid arthritis and the effect of the drug on neutrophil functions, including migration. More studies are required to solve this paradoxical situation.

1 Pham Huy D, Roch-Arveiller M, Muntaner O, Giroud J-P. In vitro and in vivo effects of gold salts chemotaxis and random migration of rat polymorphonuclear leukocytes. Agents Actions 1985; 16: 363-8.

2 Mowat A G. Neutrophil chemotaxis in rheumatoid arthritis. Effect of D-penicillamine, gold salts, and levamisole. Ann Rheum Dis 1978; 37: 1-8.

3 Elmgreen J, Ahnfelt-Ronne I, Nielsen O H. Inhibition of human neutrophils by auranofin: chemotaxis and metabolism of arachidonate via the 5-lipoxygenase pathway. Ann Rheum Dis 1989; 48: 134-8.

4 Turner R A, Johnson J A, Semble E L. Antirheumatic drug effects on neutrophil response to chemotactic factors: a comparison of analytical techniques. Proc Soc Exp Bio Med 1983; 173: 200-4

5 Hafström I, Udén A-M, Palmblad J. Modulation of neutrophil functions by auranofin. Studies on effects in vitro and in rheumatoid arthritis patients. Scand $\mathcal{F}$ Rheumatol 1983; 12: $97-105$
6 Wolach B, DeBoard J E, Baehner R L, Boxer L A Modulation of leukocyte aggregation and degranulation Modulation of leukocyte aggregation and de

7 Davis P, Miller C, Russell A S. Effect of gold compounds on the function of phagocytic cells. I. Suppression of phagocytosis and the generation of chemiluminescence. f Rheumatol 1982; 9 (suppl 8): 18-24.

8 Dimartino M J, Walz D T. Inhibition of lysosomal enzyme release from rat leukocytes by auranofin. Inflammation 1977; 2: 131-42.

9 Hurst N P, Gorjatschko L, Betts W H, Zalewski P D Forbes I J. Auranofin modulates human neutrophil superoxide production and protein phosphorylation. Rheumato Int 1989; 8: 245-50.

10 Minta J O, Williams M D. Interactions of antirheumatic drugs with the superoxide generation system of activated human polymorphonuclear leukocytes. $₹$ Rheumatol 1986; 13: 498-504.

11 Mahoney C W, Hensey C E, Azzi A. Auranofin, gold thiomalate, and gold thioglucose inhibit protein kinase $C$ Biochem Pharmacol 1989; 19: 3383-6.

12 Parente J E, Walsh M P, Girard P R, Kuo J F, Ng D S, Wong K. Effects of gold coordination complexes on neutrophil function are mediated via inhibition of protein kinase C. Mol Pharmacol 1989; 35: 26-33.

13 Hafström I, Seligmann B E, Friedman M M, Gallin J I Auranofin affects early events in human polymorphonuclear neutrophil activation by receptor-mediated stimuli f Immunol 1984;132: 2007-14.

14 Oben J A, Wallace G R, Chain B M, Foreman J C. The stimulation of IL-2 production by antirheumatic drugs. Immunology 1989; 67: 328-32.

15 Betts W H, Hurst N P, Murphy G A, Cleland L G. Auranofin stimulates LTA hydrolase and inhibits 5-lipoxygenase/LTA synthase activity of isolated human 5-lipoxygenase/LTA synthase activity of isolated

16 Oben J A, Foreman J C. Stimulatory effects of antirheumatic drugs on human neutrophil functions. rheumatic drugs on human neutropharmacology 1988; 16: 157-65.

17 Elferink J G R, de Koster B M. Stimulation of rabbit polymorphonuclear leukocyte locomotion by D-penicillamine. Biochem Pharmacol 1991; 42: 1745-50.

18 Elferink J G R, de Koster B M. Tiopronin (2-mercaptopropionyl glycine) has chemokinetic and chemotactic properties for polymorphonuclear leukocytes. Immuno pharmacology 1992; 23: 91-6.

19 Boyden S V. The chemotactic effect of mixtures of antibody and antigen on polymorphonuclear leukocytes. $\mathcal{F} \operatorname{Exp} \mathrm{Med}$ 1962; 115: 453-66.

20 Zigmond S H, Hirsch J G. Leukocyte locomotion and chemotaxis: new methods for evaluation and demonstration of a cell-derived chemotactic factor. 7 Exp Med stration of a cell-detive

21 Bray M A. Leukotrienes in inflammation. Agents Action 1986; 19: 87-99.

22 Kramer Ij $M$, Van der Bend $\mathrm{R}$ L, Tool A T J, Van Blitterswijk W J, Roos D, Verhoeven A J. 1-O-hexadecyl2-O-methylglycerol, a novel inhibitor of protein kinase $\mathrm{C}$ inhibits the respiratory burst in human neutrophils. $\mathcal{F}$ Bio Chem 1989; 264: 5876-84.

23 Wilkinson P C, Allan R B. Assay systems for measuring leukocyte locomotion: an overview. In: Gallin J I, Quie P G, eds. Leukocyte chemotaxis. New York: Raven Press, 1978: 1-24.

24 McIntyre T M, Reinhold S L, Prescott S M, Zimmerman $\mathrm{G} \mathrm{A}$. Protein kinase $\mathrm{C}$ activity appears to be required for the synthesis of platelet-activating factor and leukotriene $\mathrm{B}_{4}$ by human neutrophils. $\mathcal{F}$ Biol Chem 1987; 262: triene $B_{4}$

25 Goetzl E J, Wasserman S I, Gigli I, Austen K F. Enhancement of random migration and chemotactic
response of human leukocytes by ascorbic acid. $₹$ Clin response of human leu.
Invest 1974; 53: 813-8.

26 Anderson R, Glover A, Koornhof H J, Rabson A R. In vitro stimulation of neutrophil motility by levamisole: maintenance of cGMP levels in chemotacticall stimulated levamisole-treated neutrophils. $\mathcal{f}$ Immuno 1976; 117: 428-32.

27 Hill H R, Estensen R D, Quie P G, Hogan N A, Goldberg N D. Modulation of human neutrophil chemotactic responses by cyclic 3',5'-guanosine monophosphate and cyclic 3',5'-adenosine monophosphate. Metabolism 1975; 24: 447-56.

28 Anderson R, Glover A, Rabson A R. The in vitro effects of histamine and metiamide on neutrophil motility and their relationship to intracellular cyclic nucleotide levels. relationship to intracellular

29 Estensen $R$ D, Hill $H$, Quie $P$ G, Hogan $N$, Goldberg N D. Cyclic GMP and cell movement. Nature 1973; 245: 458-60.

30 Gruetter C A, Gruetter D Y, Lyon J E, Kadowitz P J Ignarro L J. Relationship between cyclic guanosine 3':5'-monophosphate formation and relaxation of coronary arterial smooth muscle by glyceryl trinitrate, nitroprusside, nitrite and nitric oxide: effects of methylen blue and methemoglobin. $\mathcal{f}$ Pharmacol Exp Ther 1981 219: $181-6$.

31 Schmidt M J, Sawyer B D, Truex L L, Marshall W S Fleisch J H. LY 83583: an agent that lowers intracellular levels of cyclic guanosine 3',5'-monophosphate. f Pharmacol Exp Ther 1985; 232: 764-9.

32 Finkelstein A E, Roisman F R, Batista V, et al. Ora chrysotherapy in rheumatoid arthritis: minimum effective dose. F Rheumatol. 1980; 7: 160-8. 